\title{
A Comparison of Cost-Benefit and Cost-Effectiveness Analysis in Practice: Divergent Policy Practices in Sweden
}

\author{
MIKAEL SVENSSON 1,2, * \\ LARS HULTKRANTZ ${ }^{2}$ \\ ${ }^{1}$ Health Metrics, The Sahlgrenska Academy, University of Gothenburg, Sweden \\ 2 Department of Economics, Örebro University, Sweden
}

\begin{abstract}
This paper compares the implementation of the two economic evaluation methods Cost-Effectiveness/Utility (CEA/CUA) and Cost-Benefit Analysis (CBA) as tools for allocation of national public funds in the health and transport sector in Sweden, respectively. We compare the recommended values for important economic parameters such as the social discount rate, the marginal cost of public funds, and the explicit and implicit valuation of health, and document a number of substantial and unexplained differences in implementation. Such differences are problematic considering that the increasing use of economic evaluations to guide policy decisions also has implied an overlap of application areas. We conclude with a discussion on the need of a harmonized procedure for economic evaluations in the public sector in order to reduce the risk of inefficient allocations purely due to different applications of the methods.
\end{abstract}

JEL classification: D61, I18, H51

Key words: cost-benefit analysis, cost-effectiveness analysis, cost-utility analysis, public policy

\section{Introduction}

Different types of economic evaluation methods are used to guide public policy decision making on how to allocate scarce public funds to competing investments. Cost-Benefit Analysis (CBA) is often used as a tool in e.g. environmental and transport policy around the world (see e.g. HM TREASURY 2003, Hagen et al. 2012, Mishan 1982). CostEffectiveness/Utility Analysis (CEA/CUA) is the dominant method for evaluations in the health sector (ISPOR 2013). In this paper we compare the implementation of these two evaluation methods in practical decision making using Sweden as a case study.

The principal difference between CBA and CEA/CUA is clear in theory, but more vague in practice. In $\mathrm{CBA}$, all costs and benefits are valued in monetary terms using the willingness to pay (WTP) approach so that the present values of benefits and costs can be compared. The decision rule is simple in that if the net present value of the benefits outweigh the costs the investment is said to increase social welfare according to the Kaldor-Hicks

*Correspondence to: Mikael Svensson, Health Metrics, The Sahlgrenska Academy, University of Gothenburg, Box 414, S-405 30, Gothenburg, Sweden. E-mail: mikael.svensson.2@gu.se

Published: Online February 2017. In print December 2017. dx.doi.org/10.5617/njhe.1592 
criterion (e.g. Mishan 1982). In CEA/CUA, outcomes are measured in some natural onedimensional unit (CEA) or in a multi-dimensional (in health) unit (CUA) (we will henceforth collectively refer both as CEA). When applied to evaluations in health care the most common multi-dimensional outcome is quality adjusted life years (QALY), which is the product of gained life years (the most common time unit used) and the health-related quality of life in each life year (Dolan and Edlin 2002, Kaplan and Bush 1982).

Given that costs and effects are measured in different units, a CEA can never in itself identify whether an investment increases or decreases social welfare. Instead, two decision rules have been suggested when using CEA with QALYs (or similar) as an outcome measure (Weinstein and Zeckhauser 1973) ${ }^{1}$ : (1) choose interventions in ascending order of cost per QALY until the budget is exhausted, (2) select interventions with a cost per QALY less than or equal to a specified threshold value. The second decision rule ("threshold approach") is usually what policy makers relies on. The decision rule can then slightly more formally be described as comparing the incremental cost-effectiveness ratio (ICER) to the threshold value $(\lambda)$ :

$\frac{\text { Cost }_{\text {Evaluation Alternative }}-\text { Cost }_{\text {Comparison Alternative }}}{Q A L Y_{\text {Evaluation Alternative }}-Q A L Y_{\text {Comparison Alternative }}}<\lambda \Rightarrow$ Cost-effective intervention

Under an assumption of a fixed budget and using a health-care perspective the threshold value $(\lambda)$ should be based on the value ("cost per QALY") of current services that are displaced when introducing a new cost-increasing intervention. This is e.g. the approach in the UK in the work by the National Institute of Clinical Excellence (NICE). In an attempt to estimate the average value of displaced services in the National Health Services (NHS) in the UK Claxton et al. (2013) estimate a threshold value of around GBP 13,000. In a fixed budget setting with a societal perspective an adjustment to the threshold value should be made such that non-health care consequences are properly valued (Baker et al. 2011).

Under a flexible budget assumption and societal evaluation perspective, as e.g. in the Swedish recommendations of CEA (TLV 2003), the threshold value $(\lambda)$ should rather instead be based on the societal willingness to pay for the outcome (e.g. QALY) (Baker et al. 2011). Irrespective of the perspective for deciding the threshold value, if a decision maker sets an explicit threshold value $(\lambda)$, or range of values, the decision rule can be reformulated in the net-monetary benefit approach as: $\lambda \times \Delta Q A L Y-\Delta$ Cost $>0 \Rightarrow$ cost-effective investment, i.e. a form of "quasi-CBA" where benefits and costs both can be expressed in monetary terms but without a formal foundation in welfare economic theory (Hammitt 2013). Specifically, it has been shown that the admissible utility functions under plausible preference are not consistent with one unique WTP per QALY and thus CEA with QALYs (or other "linear" life-year outcome measures) cannot be truly motivated by economic welfare theory.

Considering the similarities in real-world applications of CBA and CEA, although only the former can be formally grounded in welfare economic theory, it becomes an important issue as to whether or not they will produce similar policy guidance for a given application. While the relations of CBA and CEA to economic welfare theory have been much studied and discussed (e.g. Bleichrodt and Quiggin 1999, Dolan and Edlin 2002), less notice has been given to comparison of how the practices of the two approaches have evolved over time along their separate lines. The aim in this paper is therefore to compare current practices of the two approaches, using Sweden as a reasonable approximation of a current-practice case.

\footnotetext{
${ }^{1}$ Assuming perfect divisibility and constant returns to scale in all interventions.
} 
We base our comparison on the only two formal guidelines for conducting CBA and CEA from Swedish government authorities. For CBA this comes from the Swedish Transport Administration (henceforth STA) with annual updates. For CEA we rely on the guidelines published by the Dental and Pharmaceutical Benefits Agency (henceforth TLV), with the current guidelines being from 2003 with minor revisions conducted in $2014 .^{2}$ Key indicators from economic evaluations significantly affect high-stake economic decisions in both sectors. $^{3}$

The rest of the paper is structured as follows. In section two we discuss the roles of CBA and CEA in allocation of public funds in Sweden. Section three reviews how some generic real-world complexities that arise in economic evaluations are handled. Section four compares some frequently used economic parameters, while section five concludes the paper with a discussion.

\section{CBA and CEA practices for allocation of public funds in Sweden}

\subsection{CBA implementation: history and practices}

The first textbooks on $\mathrm{CBA}^{4}$ appeared in the 1950s and from the 1960s usage became widespread for analysis of development aid projects and national infrastructure planning; later on also for economic evaluation of, among others environmental policy and labourmarket policy programmes. In Sweden, the National Road Administration started using CBA for evaluation of national road investment objects in the 1960s. Now STA takes the responsibility to maintain and develop the CBA models.

The importance of CBA seems to have increased over time for decision making in Swedish infrastructure planning, even though societal efficiency is still far from the main criteria in decision making, especially regarding projects specifically selected by politicians. In an evaluation of how the CBA of investments in the national transport plan for 20102021 affected prioritizations, Eliasson and Lundberg (2011) found that projects with a higher benefit-cost ratio indeed had a significantly higher probability of being included. More specifically, decision makers seemed to use economic evaluations to exclude unprofitable projects, whereas among profitable projects the relationship between the benefit-cost ratio and prioritization was weaker. A subsequent study limited to road projects by Eliasson et al. (2014) showed that for road projects priorities made by the STA more strongly followed the CBA ranking than those subsequently made by the government.

\subsection{CEA implementation: history and practices}

CEA with QALYs as an outcome measure has a more recent history as an input to decision making. In Sweden, TLV was set up in 2002 for, among other things, the task of determining which prescription drugs that should be reimbursed (subsidized) in the national

\footnotetext{
2 The guidelines can be accessed from the website of the two governmental authorities, respectively. CBA guidelines for the transport sector: http://www.trafikverket.se/Foretag/Planera-och-utreda/Planerings--ochanalysmetoder/Samhallsekonomisk-analys-och-trafikanalys/Gallande-forutsattningar-och-indata/.

CEA guidelines for the health/pharmaceuticals sector: http://www.tlv.se/tlv/regelverk/allmanna-rad/.

3 Several other government agencies such as the Environmental Protection Agency, The National Board of Health and Welfare, the Swedish Council on Technology Assessment in Health Care also make such evaluations but without their own explicit method recommendations, but rather to a large extent following the procedures and guidelines set out by the STA and TLV.

4 The roots of CBA can be traced back in the U.S. to a recommendation by the Secretary of the Treasury Albert Gallatini 1808 on comparison of costs and benefits in water related projects, and in Europe to the analysis of the economics of bridges in 1844 by the French engineer and economist Jules Dupuit.
} 
pharmaceutical benefits scheme. A producer with a new drug innovation that seeks reimbursement submits a CEA ${ }^{5}$ for the drug using a company-suggested price; on the basis of the application, TLV decides on subsidization for all patients, sub-groups of patients or no patients at all. TLV is to consider principles of human dignity, need and solidarity as well as cost-effectiveness (ex-ante evaluation). This means that TLV explicitly prioritizes diseases with more severe consequences and diseases for which few or no treatment alternatives exist, but otherwise cost-effectiveness, expressed as cost per QALY is stated to be a guiding principle (e.g. Franken et al. 2013, Persson, Svensson, and Pettersson 2012). It is a so-called Value Based Pricing (VBP) system where the subsidization decision by TLV, using the company-suggested price, should be based on the value of the positive future benefits the medical technology will produce in the population; where the economic value is related to the willingness of the population to pay for the health improvements.

TLV also continuously evaluates different pharmaceutical areas regarding whether or not a drug should keep being subsidized at current prices (ex-post evaluation). In some cases, the sheer initiation of such evaluations may lead to price decreases by the pharmaceutical companies in order to keep the subsidies for a drug, which was the case when an evaluation was made of previously subsidized drugs for weight reduction (Persson, Willis, and Ödegaard 2010).

There are general guidelines for how the cost-effectiveness should be conducted by submitting drug companies, ${ }^{6}$ and there is also a manual that more specifically outlines the practical procedures for submitting applications ${ }^{7}$. These include details such as: the main effect measure is recommended to be QALYs, and if data is based on intermediate effect measures ("surrogate end-points"), modelling should be conducted in order to translate these into gained QALYs. In some cases, where QALYs may be difficult to use, CBA with WTP measures may be acceptable. Lost production due to treatment and morbidity should be included using the human-capital approach. Up until very recently it was stated that if treatment affects survival, all costs due to increased survival should be included (net of total consumption and production for the gained life years), which is in line with theoretical conclusions (Johannesson and Meltzer 1998, Jönsson 2009). However, heavy criticism was voiced from the public and patient advocacy groups over the inclusion of costs of added life years (specifically related to the declined reimbursement for the prostate cancer drug Zytiga ${ }^{\circledR}$ in 2012), which had the effect that guidelines were updated so as to suggest to conduct analyses both including and excluding cost of added life years (see the theoretical discussion on this in e.g. Nyman 2004, van Baal et al. 2011).

As regards the impact of cost-effectiveness on decision making, studies have suggested that the importance of cost-effectiveness in the decision-making process is more significant at central, as compared to decentralized, level (Hoffmann and Graf von der Schulenburg 2000). Anell and Persson (2005) evaluated decisions made in Sweden between 2002 and 2005 and found that the importance of cost-effectiveness varied significantly across pharmaceutical groups. For example, it seemed that CEA played a very minor role regarding decisions for orphan drugs, i.e. drugs targeting a very rare medical condition, whereas it seemed to be more important for drugs with a significant budget impact, for example drugs targeting hypertension. A recent paper analysing all decisions made by TLV between 2005 and 2011 shows that both the need and solidarity principle (measured as

\footnotetext{
${ }^{5}$ Or cost analysis, if the drug is cheaper and with similar or better effect. This should be noted given the literature indicating that there may be biases with cost (minimization) analysis even if the health effects have been shown not to be significantly different between two treatment options (Dakin and Wordsworth 2013).

${ }^{6}$ Available online: http://www.tlv.se/lakemedel/pris-och-subvention-av-lakemedel/halsoekonomi/

${ }^{7}$ Available online: http://www.tlv.se/Global/TLVDokument/20121220-handbok-ansokan-subventionpris.pdf.
} 
disease severity) and the cost-effectiveness principle were significant determinants of policy reimbursement decisions (Svensson, Nilsson, and Arnberg 2015).

\section{The evaluation starting point - maximization and the budget constraint}

A CBA or CEA seeks to find the options in a choice set that give the highest benefit (utility or health) subject to constraints. ${ }^{8}$ In a CBA this is done by choosing projects based on the highest net present value, or, if there is a fixed capital budget, based on the maximization of the fixed budget (e.g. by choosing based on the highest benefit-cost ratio). In CEA this implies, as was outlined in the introduction, choosing projects with the lowest cost per outcome unit (e.g. gained QALYs).

Two issues that must be dealt with ex-ante often have a fundamental impact on the outcome. One is the budget constraint and the second is related to the choice of the "reference or "default" alternative". ${ }^{9}$ The budget constraint is present in all economic problems and it can be explicit (considered ex ante by the decision maker) or implicit (ex post). In the ex post case "someone else" is picking up the bill, but the budget constraint may still be present in the selection procedure through formal or informal conditions on which the decisions are based. The budget constraint is often not perfectly known when decisions are made. For instance, the selection process may be sequential, so that the decisions made at an early stage are based on guesses on how scarce these funds will be at the end. Further, there may be not just one but several budget constraints. Public budgets are often determined for a short period at a time (for instance a year), but can have budget consequences for much longer periods. It is not uncommon that there are budget consequences across generations, and thus society faces an intertemporal budget constraint. Finally, the consequences of all actions are not completely described, i.e., some important effects cannot be quantified and/or valued (in either monetary or QALY terms). The decision maker then has to consider some effects aside from these.

Regarding the choice of the default or reference alternative, the different alternatives se may be mutually exclusive (competing) or independent. An example of mutually exclusive projects is if a patient will use one drug to reduce hypertension, not several. Mutually independent projects are programs that may be used in combination to affect the outcome of relevance, for instance one drug can be used to improve life expectancy together with a drug that reduces pain in a given set of a disease population (and there is no correlation between the two). However, real-world choice sets are often not limited or clearly defined. There can be many; sometimes even infinitely many, possible actions, so it is not always obvious what the evaluation default is. This poses potential dangers with economic evaluations considering that it is possible to purposely choose inferior reference alternatives to improve the cost-efficiency of some investment. Hence, analysts and decision-makers must carefully consider if all relevant alternative measures have been included in the evaluation.

\subsection{Effective budget constraint}

An often noted fundamental difference between CBA and CEA is that a CEA can never indicate the optimal level of funding going into new medical technologies/health interventions; however, it may be useful in order to rank and evaluate projects when there is a predetermined fixed budget (e.g. Weinstein and Zeckhauser 1973). On the other hand,

\footnotetext{
${ }^{8}$ See Boadway (2006) for an overview of the principles of benefit-cost analysis.

${ }^{9}$ Another potentially important constraint comes from the irreversibility (sunk cost) nature of many investments, which introduces a choice between investing now (wholly or partly) or later.
} 
CBA can be used to maximize social welfare without a predetermined budget allocation to different sectors. Looking at practical applications by STA and TLV, however, this distinction is considerably blurred. If a simple characterization must be made, it should be that it is the other way around in a real-world setting, i.e., the CBA starts from a budget constraint while CEA builds on an open budget, since the final effect on public expenditure of the decision to approve a new product depends, among other things, on how doctors and patients respond in their prescriptions and consumption. ${ }^{10}$

TLV has no explicit budget to take into consideration in each respective reimbursement decision, and e.g. budget impact analyses are not seen (at least not explicitly) as an important part of the reimbursement application package (Shah et al. 2014). ${ }^{11}$ However, although indirectly TLV has to comply with the overall drug bill (where costs are shared between the national government, the county councils, and patients' co-payments). But, given that TLV has rough and informal guidelines on an interval of acceptable monetary shadow values of a QALY, it is quite unlikely that a new medical technology with proven significant clinical effects, and an ICER well below the informal shadow value, would be refused reimbursement/subsidization. Since TLV does not have any formal control of the number of incoming applications or innovations of new technologies, a surge in new efficient technologies that targets larger patient populations will have significant health care budget effects. ${ }^{12}$

In comparison, the national infrastructure planning is based on an explicit budget for a ten-year period, even though the national state budget is decided by the Parliament one year at a time. Before the work on a new plan starts, the Parliament decides on a budget frame, which thus is a formal, but not binding, commitment to allocate resources within the next ten annual budgets. For instance, the national plan for the period 2010-2021, was based on a decision in 2008 to grant 156 billion SEK (17 billion Euros) to new investments. It is thus fair to say that the planning process was based on an explicit ex ante budget constraint. However, this constraint could be quite flexible under specific conditions. For instance, separate from the preparation of the national plan, a study was commissioned to evaluate a new high-speed rail line, expected to cost 145 billion SEK and to be carried out during the same period as the national plan. Therefore, while the aim of the CBA in the planning process is mostly thought of as a guide to decision-making on relative ordering of investment objects, it is also used in decisions affecting the size of the total investment budget.

\subsection{Multiple budget constraints}

Another issue in both transport and health sector planning is that decisions often have enduring budgetary consequences that extend beyond the period for which a budget constraint is considered. For instance, a decision to reimburse a new type of medical intervention will draw on public budget funds for a long time, with multi-temporal budget constraints as a consequence. This can be handled in two alternative ways. One possibility is to explicitly set up and solve a multi-period optimization problem, including choice sets and budget constraints of future periods. However, the information needed to do that is

\footnotetext{
${ }^{10}$ In the CEA literature this is referred to as the "opportunity cost" or "affordability" issue (Gafní and Birch 2007 a, b, Drummond 2007). Of course, in the end there will always be an effective budget constraint, but not necessarily at the level of total funds for remuneration of pharmaceutical products.

${ }^{11}$ At regional/county council level and hospital/clinic level the link to budget impact is substantially more direct and in reimbursement decisions that fall on these actors the budget impact is a fundamental input into the decision making.

12 This effect or intrinsic conflict has been discussed in e.g. Persson et al. (2012).
} 
seldom present. A second option, that requires less specific information, is to evaluate future budgetary effects with shadow prices that reflect the expected relative scarcity of budget funds in future periods.

Gafni and Birch (2006) and Birch and Gafni (2007) have suggested that the use of a constant monetary value of a QALY in evaluation of new health technologies may give cost growth (Gafni and Birch 2006, p.2095). ${ }^{13}$ This would be the case if the drug benefits approval process works in a ratchet-like manner, i.e., there is an inflow of new products but no outflow as new products are compared to old. But to what extent this is the case depends on the duration of the approval. If a sunset review is required after some time, the decision can be re-considered in view of later developments. Further, sunset reviews may decrease costs via the mechanism that companies reduce prices in order to pass the reviews, which happened, as discussed previously, with hypertension drugs in Sweden (Persson, Willis, and Ödegaard 2010). Total expenditure on pharmaceuticals and other medical non-durables in Sweden has increased to a lesser degree than other health care costs in recent years, in contrast to the time period before TLV started its work in 2002 (OECD 2015). The trend in pharmaceuticals expenditure is obviously driven by many factors, but there is at least no clear sign that the new procedures have led to a "cost explosion" as some authors have feared. ${ }^{14}$

In infrastructure, a ratchet effect can be associated with maintenance. New infrastructure therefore adds to future needs for funding maintenance. In some countries (for instance the UK), maintenance costs are included in the "cost denominator" of the benefitcost ratio. In Sweden these costs are instead subtracted from the "benefits numerator" and are therefore not limited by the initial budget constraint. A possible source of bias for tradeoffs between up-front investment expenditure and future maintenance cost is therefore that planners have an incentive to trim investment expenditure so as to squeeze in a project in the investment plan, which may lead to unnecessary high maintenance needs. Noteworthy is that one of the main motives for Public Private Partnership contracting of infrastructure projects in Sweden is a wish to promote a life cycle perspective on total costs, which indicates that regular public funding introduces some inter-temporal bias.

\section{Economic parameters}

\subsection{Value of life and the lambda value: Practice and evidence}

As previously observed, some of the alleged main differences between CBA and CEA are blurred when one takes a closer look at actual practices. This is particularly true when it comes to the economic evaluation of effects on mortality and morbidity

The monetary values of mortality and morbidity effects as used in CBA are represented by the value of a statistical life (VSL), value of a statistical severe injury (VSSI) and the value of a statistically light injury (VSLI), see e.g. Hultkrantz and Svensson (2012) for a recent review. VSL is thought to represent the consumer preferences for avoiding one "statistical" fatality and in the Swedish guidelines values of VSSI and VSLI are estimated

\footnotetext{
${ }^{13}$ Specifically, they attribute an increase in NHS expenditures of UKP 836 million in 2005 as being an unplanned increase in resources caused by the use of a threshold level that is invariant to the change in the opportunity cost of available funds as more products pass the threshold. They also refer to the case in Australia where CEA used to determine changes in the pharmaceutical benefits program, were shown to be associated with costs increases of over 14 percent per annum over the first ten years after introduction. But to the knowledge of the authors there are no quasi-experimental studies that have properly evaluated this issue.

14 This expenditure rose in real terms by 44 percent $1995-2000$, 14 percent 2000-2005, and 11 percent 20052010 (OECD 2012). One reason for the reduced cost increase has been shown to be the generic substitution reform (Granlund 2010).
} 
as fixed shares of the VSL. All estimates are thus willingness-to-pay based and the STA currently recommends a VSL of 23.7 million SEK (approx. USD 2.7 million; 1 USD $=8.83$ SEK).

CEA with QALYs as the outcome measure has been (assuming independence between programs and constant returns to scale) motivated from a decision making perspective such that programs are chosen with most cost-effective programs picked first, up until the budget is exhausted. In such a scenario the "value" of a QALY (the "lambda" value) will be implicitly determined. However, since decision makers never have information about the cost-effectiveness of all potential programs, they instead use a threshold rule (or an interval of values), whereby programs will be implemented if the ICER (in terms of the cost per gained QALY) is lower than a certain threshold value. Although it does not have a definite threshold value, TLV has a range of such values "inspired" by the VSL used by STA. This range can partly be traced to Persson and Hjelmgren (2003), who used a modelling technique based on (now dated estimates of) VSL to implicitly derive a WTP for a QALY. This approach resulted in a WTP per QALY of approximately SEK 655,000 in factor prices (USD 74,000), which in the price level of 2013 is approx. 770000 SEK (USD 87,000). Inspecting the actual decisions taken by TLV indicates that they have actually reimbursed new technologies with a cost per QALY of 1.2 million SEK (USD 136,000), but also declined reimbursement to technologies with a cost per QALY at 700000 SEK (USD 79,000), i.e. their implicit WTP for a technology may be said to be in this range (Svensson, Nilsson, and Arnberg 2015).

At first glance, it may seem to be in the interest of overall efficiency in the CBAsense to use an ICER cut-off level (i.e., the lambda) in the health sector that is consistent with values used to make economic assessments of traffic safety. However, that presumes that consumers really are indifferent to whether a life (year) is gained by a safety enhancement program in the transport sector or a health technology improvement. It is unclear if this is the case since almost all published evidence on VSL in Sweden is based on mortality risks in an infrastructure context. Based on international evidence there is, however, no robust evidence that preferences should differ substantially between risk/health domains (Lindhjelm et al. 2011). Further, since the cost per QALY of a new technology is mostly based on the producer suggested price, the cost per QALY is endogenous (Jena and Philipson 2013). For products that pass the CEA evaluation, the price paid by consumers will not depend on the full price charged by the producers, so these producers have no incentives to lower the price below what is required to go below what they believe is necessary to secure reimbursement.

\subsection{Discounting}

Discount rates used in the transport and health sectors in Sweden are 3.5 and 3 percent, respectively. The reason for discounting being at different rates in two different fields of budget allocation within the same national government is obscure. The choice of rate is motivated for the transport sector only. The most recent adjustment was made in 2010 when the rate was reduced from 4 to 3.5 percent for CBA in the transport sector. It was based on the same principles (the Ramsey equation) and parameters as those used in the UK (HM TREASURY 2003), which, with a projected average growth rate of 1.78 percent, resulted in a discount rate of 3.5 percent. ${ }^{15}$

The recommendations of a 3 percent discount rate by TLV is not motivated in the guideline, but it is in line (or close to) what is usually adopted as a discount rate in health economic evaluations and as suggested by the US panel on cost-effectiveness (Siegel et al.

\footnotetext{
${ }^{15}$ It should be noticed that these are risk-free rates.
} 
1996). A complexity with discounting in a CEA context is that if QALY weights have been elicited using time trade-off, time-preferences are already captured in the QALYs. Hence, it may lead to double-discounting if the health effects in the CEA are discounted (Johannesson, Pliskin, and Weinstein 1994).

A related issue which has been largely ignored until recently concerns real price changes. In CBA, future relative prices are normally assumed to remain constant. However, some relative prices, notably the value-of-travel-time-savings, values of safety and health, and values of some environmental goods that are limited in supply, are likely to increase with income growth. Several recent empirical studies have provided evidence on how the willingness to pay for various benefits increases with income changes over time. For example, Hammitt and Robinson (2011) review longitudinal studies and cross-country comparisons which suggest that the income elasticity of the value of statistical life may be considerably larger than one.

Ignorance of future relative price changes may have been a serious flaw of the CBA practices. These have now been changed in several European countries, for instance the UK and Norway. In Sweden, since 2012, all future benefits and costs valued by willingness-topay elicitation are inflated with the prospected growth of GDP per capita. Interestingly, this casts new light on the CEA discussion on having separate rates of discount for utility and costs, as a lower discount rate for benefits could be, slightly depending on the chosen perspective, justified by an expectation of rising real value of health improvements (Claxton et al. 2011).

\subsection{Marginal cost of public funds}

There is an excess burden, associated with taxes, borne by public funding (e.g. Dahlby 2008). In a study by Birch Sörensen (2010) it was estimated that the marginal cost of public funds (MCPF) for a proportional increase of the income tax on labor is 1.32. This implies that every tax "krona" (SEK) used to fund a new medical technology or infrastructure investment the societal cost is $32 \%$ higher.

For this reason, in CBA in Sweden public investment expenditure is multiplied by a factor of 1.3, representing the marginal cost of public funds (MCPF). TLV recommendations for cost-utility analysis do not include any mention of MCPF at all. Hence, implicitly it may be argued that this recommendation assumes the MCPF to be equal to unity.

In an evaluation setting based on a strict health care perspective (e.g. the UK NICE case) where broader societal costs and benefits are not included, it is not necessary to include an adjustment for the MCPF since relative rankings would not be affected.

However, considering that TLV recommends a societal perspective and argues to use a demand-based threshold value of a QALY ("value-based pricing"), MCPF should be included as it constitutes an additional societal cost associated with the funding.

\section{Discussion}

In this paper, we have described, discussed and compared CBA and CEA methods as they are used by two Swedish government authorities. The range of policy fields and government agencies that make use of CBA and CEA has widened during the last ten years, and the role given to economic evaluations has increased in some fields. This development has gone hand in hand with considerable effort in developing models for planning and evaluation purposes.

The most important inherent difference between the CBA and CEA is related to the different perspectives on mortality and morbidity effects, and this is also reflected in the 
Swedish practices. First and foremost, the CBA tradition has a focus on life vs. death, while CEA focuses on life (quality-adjusted) years lost or gained. The choice between these perspectives is a matter of normative economics, ethics, and possibly politics, and it has important ramifications for priorities. It is by now robustly demonstrated that the "value per life" expressed as the VSL varies by the number of life-years saved. Further, it is well established that the use of a constant value per life-year is not in line with individual preferences or theoretically possible given plausible assumptions.

Summing up this discussion, given that theoretical as well as empirical evidence tends to show that to prioritize life-saving programs targeting younger age-groups (or more correctly groups where we can save more expected life-years) is in line with societal preferences implies that the current CBA approach of using a constant VSL irrespective of age of individuals "saved" is not in line with public preferences. But, the empirical evidence is not in line with the QALY-approach as mostly used in practice either, such that a life year is valued equally across age-groups or that the willingness to pay is proportional to the number of life years saved. The willingness-to-pay approach of CBA is quite flexible and can easily be adjusted so as to differentiate health and safety effects with respect to the number of life years lost or gained (if not quality of life). We can see no obvious reason why CBA should not make such differentiation; at least as a sensitivity analysis, when that is relevant, for instance in evaluation of traffic safety measures for school children. It is slightly more difficult to adjust the practices of CEA using QALYs (or some other life-year measure) to satisfy some of the welfare theoretic foundations; one approach to move in this direction would be to acknowledge that the threshold value should differ with respect to the total number of gained QALYs from a technology (the value per QALY decreases with the total number of QALYs gained). It is sometimes argued in the CEA-literature that the connection to welfare theory is of no particular interest (e.g. the extra-welfarism literature). However, if there is no interest in the policy community of consistency with welfare theory then it is of importance to acknowledge that we are not doing health economics, but maybe e.g. operations research and the analyses are not comparable or trying to measure equal entities.

Another important difference as shown in our comparison is the real-world implementation of budget constraints. Contrary to the textbook version, CBA is formally conducted within a given budget frame, while CEA is done without any explicit consideration of budgetary consequences in Sweden. However, both methods are becoming more comprehensive, including different aspects of complex decision problems, and it seems that one aspect of this is that evaluations are being used as tools for deciding how much to do (budget allocation across sectors), not just what to do within a sector. In the health sector, this has already led to an approach where the threshold values are not directly determined from a budget constraint; in the transport sector the budget constraints are "flexible".

In CEA, international practices have developed mainly within the health care perspective where "effect" relates to health and "cost" to the direct and indirect cost of treatment. However, in many cases, also within healthcare, "treatments" or "measures" have multiple purposes and both effects and costs are multidimensional and borne by various subjects (health care budgets, patients, employers, etc.). There is a need for analysis that includes various effects and therefore to close the gap to CBA, while still preserving an emphasis on QALY measures. The Swedish practices have gone some way in this direction; on the cost side by requiring that non-clinical costs such as productivity losses, costs of waiting, etc. should be considered. On the benefit side, the indicative values that are used are broadly consistent with the VSL level used for CBA in other sectors, and several recent studies of health technologies are perhaps better classified as CBA than CEA, although there 
are "broken links" to welfare theory (e.g. Lundqvist et al. 2013). Also, outside the health sector, economic evaluations are increasingly made up of programs and measures where some objectives concern physical risks, health and/or quality of life, for example in urban planning for pedestrians and cyclists, drug-abuse prevention, programs supporting the nutrition and physical strength of the elderly, etc. In some studies of such issues, various "hybrids" of CEA and CBA are already being used (Jaldell 2013).

In the sense that the economic evaluations also have consequences for the size of the budget (allocative issues), it is of importance that evaluations are "fair" across sectors with regards to economic parameters, e.g. the social discount rate, the marginal cost of public funds etc. An implication for current practices is thus that the discount rates used by STA and TLV (and other governmental authorities) should be set to the same rate (as there is no empirical evidence indicating that society discounts differently across these sectors) and the TLV should revise its guidelines to include the marginal cost of public funds in CEA of new medical technologies. This may further lead to the conclusion that such parameters, and perhaps general guidelines on evaluation methods, should be decided at a central government level, e.g. at the Ministry of Finance.

In order for economic evaluations of infrastructure investments and health technologies to develop and keep up with consumer preferences, it is necessary to have principles for how to revise and update parameter values. The CBA protocol has been developed over a long time in regular revisions that have engaged several government agencies with help from domestic and international expertise. It has also been supported by considerable research funding that has been granted directly by the transport agencies to fill in knowledge gaps that have been identified in the revisions. Over time this has made the CBA models more sophisticated and more encompassing with respect to various aspects of the transport system. This has largely enhanced the respect for and acceptance of the CBA routines within the agencies, the political decision-makers, and the general public. We believe that the development of harmonized European guidelines, as pioneered by HEATCO, can have similar effects at the European level.

To sum up, the comparison of real-world implementation of CBA and CEA leads us to conclude that here is a role for central government to set principles and overall economic parameters for securing quality, cost efficiency across sectors and that the opportunity cost of resources is taken into account. In transport, evaluation methods should be open for differentiation of values of safety and health improvements to take into account remaining life years, possibly also quality-of-life. In health, we notice that the use of a WTP-based lambda in Sweden has opened up for more comprehensive evaluations in the health sector and in other fields, such as social policies. Further, there are a number of inconsistencies with current guidelines of CEA as recommended by TLV, e.g. regarding the marginal cost of public funds, which should be addressed if TLV are to follow their own goal of using a societal evaluation perspective.

\section{Conflicts of interest}

The authors have no conflicts of interest to report.

\section{References}

Anell, A. and Persson, U. (2005). Reimbursement and clinical guidance for pharmaceuticals in Sweden: do health-economic evaluations support decision making? Eur J Health Econ 6(3), 274-279.

Baker, R., Chilton, S., Donaldson, C., Jones-Lee, M. W., Lancsar, E., Mason, H., Metcalf, H., Pennington, M. and Wildman, J. (2011). Searchers vs Surveyors in Estimating the Monetary 
Value of a QALY: Resolving a Nasty Dilemma for NICE. Health Economics, Policy and Law $6,435-447$.

Birch, S. and Gafni, A. (2007). Economists' dream or nightmare? Maximizing health gains from available resources using the NICE guidelines. Health Econ Policy Law 2( 2), 193-202.

Birch Sörensen, P. (2010). Swedish Tax Policy: Recent Trends and Future Challenges. Report to the Expert Group on Public Economics, ESO 2010:4, Ministry of Finance, Stockholm, Sweden.

Bleichrodt, H. and Quiggin, J. (1999). Life-cycle preferences over consumption and health: when is cost-effectiveness analysis equivalent to cost-benefit analysis? Journal of Health Economics 18(6), 681-708.

Claxton, K., Martin, S., Soares, M., Rice, N., Spackman, E., Hinde, S., Devlin, N., Smith, P. and Sculpher, M. (2013). Methods for the Estimation of the NICE Cost Effectiveness Threshold. CHE Research Paper 81, Centre for Health Economics, The University of York.

Claxton, K., Paulden, M., Gravelle, H., Brouwer, W. and Culyer, A. J. (2011). Discounting and Decision Making in the Economic Evaluation of Health-Care Technologies. Health Economics 20(1), 2-15.

Dahlby, B. (2008). The Marginal Cost of Public Funds - Theory and Applications. MIT Press Cambridge, Mss.

Dakin, H. A. and Wordsworth, S. (2013). Cost-Minimisation Analysis versus Cost-Effectiveness Analysis, Revisited. Health Economics 22, 22-34.

Dolan, P. and Edlin, R. (2002). Is it really possible to build a bridge between cost-benefit analysis and cost-effectiveness analysis? Journal of Health Economics 21(5), 827-843.

Eliasson, J. and Lundberg, M. (2011). Do Cost-Benefit Analyses Influence Transport Investment Decisions? Experiences from the Swedish Transport Investment Plan 2010-21. Transport Reviews 32(1), 29-48.

Franken, M., Nilsson, F., Sandmann, F., Boer, A. and Koopmanschap, M. (2013). Unravelling Drug Reimbursement Outcomes: A Comparative Study of the Role of Pharmacoeconomic Evidence in Dutch and Swedish Reimbursement Decision Making. PharmacoEconomics 31(9), 781-797.

Gafni, A. and Birch, S. (2006). Incremental cost-effectiveness ratios (ICERs): The silence of the lambda. Social Science \& Medicine 62, 2091-2100.

Granlund, D. (2010). Price and welfare effects of a pharmaceutical substitution reform. J Health Econ 29(6), 856-865.

Hagen, K. P., Bertnsen, S., Bye, B., Hultkrantz, L., Nyborg, K., Pedersoen, K. R., Sandsmark, M., Holst, G. and Åvitsland, G. (2012). Cost-Benefit Analysis. Norges offentlige utredninger, 2012:16.

Hammitt, J. (2013). Admissible utility functions for health, longevity, and wealth: integrating monetary and life-year measures. Journal of Risk and Uncertainty 47(3), 311-325.

Hammitt, J. K. and Robinson, L. (2011). The Income Elasticity of the Value per Statistical Life: Transferring Estimates between High and Low Income Populations. Journal of Benefit Cost Analysis 2(1).

HM TREASURY (2003). The Green Book - Appraisal and Evaluation in Central Government. Treasury Guidance London TSO.

Hoffmann, C. and Graf von der Schulenburg, J. M. (2000). The influence of economic evaluation studies on decision making. A European survey. The EUROMET group. Health Policy 52(3), 179-192.

Hultkrantz, L. and Svensson, M. (2012). The Value of a Statistical Life in Sweden: A Review of the Empirical Literature. Health Policy 108, 302-310.

ISPOR (2013). International Society for Pharmacoeconomics and Outcomes Research: Pharmacoeconomic Guidelines around the World. Available at: http://www.ispor.org./peguidelines/index.asp. 
Jaldell, H. (2013). Cost-benefit analyses of sprinklers in nursing homes for elderly Journal of Benefit Cost Analysis 4(2), 209-235.

Jena, A. B. and Philipson, T. J. (2013). Endogenous cost-effectiveness analysis and health care technology adoption. Journal of Health Economics 32(1), 172-180.

Johannesson, M. and Meltzer, D. (1998). Some reflections on cost-effectiveness analysis. Health Economics 7(1), 1-7.

Johannesson, M., Pliskin, J. S. and Weinstein, M. C. (1994). A note on QALYs, time tradeoff, and discounting. Med Decis Making 14(2), 188-193.

Jönsson, B. (2009). Ten arguments for a societal perspective in the economic evaluation of medical innovations. Eur J Health Econ 10(4), 357-359.

Kaplan, R. M. and Bush, J. W. (1982). Health-related quality of life measurement for evaluation research and policy analysis. Health Psychology 1, 61-80.

Lindhjelm, H., Navrud, S., Braathen, N. A. and Biausque, V. (2011). Valuing Mortality Risk Reductions from Environmental, Transport, and Health Policies: A Global Meta-Analysis of Stated Preference Studies. Risk Analysis 31(9), 1381-1407.

Lundqvist, A., Wilking, N., Gerdtham, U. G., Persson, U. and Steen Carlsson, K. (2013). Målinriktad behandling av bröstcancer. Studieförbundet Näringsliv och Samhälle (SNS) Stockholm, Sweden.

Mishan, E. J. (1982). Cost-Benefit Analysis. London, UK, George Allen \& Unwin, 3rd edition.

Nyman, J. A. (2004). Should the consumption of survivors be included as a cost in cost-utility analysis? Health Economics 13(5), 417-427.

OECD (2015). OECD Health Data 2015.

Persson, U. and Hjelmgren, J. (2003). Hälso- och sjukvården behöver kunskap om hur befolkningen värderar hälsan. Läkartidningen 100(43), 3436-3437.

Persson, U., Svensson, J. and Pettersson, B. (2012). A New Reimbursement System for Innovative Pharmaceuticals Combining Value-Based and Free Market Pricing. Applied Health Economics and Health Policy 10(4), 217-225.

Persson, U., Willis, M. and Ödegaard, K. (2010). A Case Study of Ex Ante, Value-based Price and Reimbursement Decision-making: TLV and Rimonabant in Sweden. European Journal of Health Economics 11(2), 195-203.

Shah, S. M. B., Barron, A., Klinger, C. and Wright, J. S. F. (2014). A Regulatory Governance Perspective on Health Technology Assessment (HTA) in Sweden. Health Policy 116(1), $27-$ 36.

Siegel, J. E., Weinstein, M. C., Russell, L. B. and Gold, M. R. (1996). Recommendations for Reporting Cost-effectiveness Analyses. JAMA 276(16), 1339-1341.

Svensson, M., Nilsson, F. O. and Arnberg, K. (2015). Reimbursement Decisions for Pharmaceuticals in Sweden: The Impact of Disease Severity and Cost Effectiveness. Pharmacoeconomics 33(11), 1229-1236.

TLV (2003). Läkemedelsförmånsnämndens allmänna råd. The Dental and Pharmaceutical Benefits Agency LFNAR 2003:2, Tillgänglig online: http://www.tlv.se/tlv/regelverk/allmanna-rad/). .

van Baal, P. M., Wong, A., Slobbe, L. J., Polder, J., Brouwer, W. F. and de Wit, G. A. (2011). Standardizing the Inclusion of Indirect Medical Costs in Economic Evaluations. PharmacoEconomics 29(3), 175-187.

Weinstein, M. and Zeckhauser, R. J. (1973). Critical Ratios and Efficient Allocation. Journal of Public Economics 2, 147-157.

(C) 2017 by the author(s). This article is an open access article distributed under the terms and conditions of the Creative Commons Attribution license (http://creativecommons.org/licenses/by/4.0/). 